\title{
Minireview
}

\section{Notch signalling in cancer progression and bone metastasis}

\author{
N Sethi' ${ }^{1,2}$ and $Y$ Kang $^{*, 1,3}$ \\ 'Department of Molecular Biology, Princeton University, Washington Road, LTL 255, Princeton, NJ 08544, USA; ${ }^{2}$ Robert Wood Johnson Medical School, \\ Piscataway, NJ 08544, USA; ${ }^{3}$ Genomic Instability and Tumor Progression Program, Cancer Institute of New Jersey, New Brunswick, NJ 08903, USA
}

Classically known for its indispensible role in embryonic development, the Notch signalling pathway is gaining recognition for its regulation of adult tissue homoeostasis and aberrant activation in disease pathogenesis. The pathway has been implicated in cancer initiation and development, as well as early stages of cancer progression by regulating conserved cellular programs such as the epithelial-to-mesenchymal transition. We recently extended the role of Notch signalling to late stages of tumour progression by elucidating a stroma-dependent mechanism for the pathway in osteolytic bone metastasis. Of clinical significance, disrupting the Notch pathway and associated molecular mediators of Notch-dependent bone metastasis may provide novel therapeutic strategies to combat aggressive bone metastatic disease.

British Journal of Cancer (201 I) I05, I805- I8I0. doi:I0.1038/bjc.201 I.497 www.bjcancer.com

Published online 10 November 201।

(c) 201 I Cancer Research UK

Keywords: Notch signalling; bone metastasis; Jagged I; tumour progression

\section{THE NOTCH SIGNALLING PATHWAY}

The Notch pathway regulates cell fate decisions during embryonic development by facilitating short-range signalling between neighbouring cells that are in physical contact. Initially discovered for yielding a 'notched' wing phenotype in Drosophila due to a partial loss of function, the pathway has since been implicated in specifying the development of several different tissues and organisms (Artavanis-Tsakonas et al, 1999). In a contextdependent manner, Notch signalling coordinates a wide range of fundamental processes and cellular programs including proliferation, apoptosis, migration, growth, and differentiation. The pathway has only recently been associated with the maintenance of adult tissue and pathogenesis of cancer.

The four mammalian Notch receptors are single-pass type-1 transmembrane proteins that are expressed on the cell surface (Logeat et al, 1998). The extracellular domain contains epidermal growth factor (EGF)-like repeats that are responsible for ligand binding and a negative regulatory region that prevents receptor activation in the absence of ligands. The intracellular domain of Notch receptors contain three common regions: (1) a subtransmembrane region that associates with transcriptional components in the nucleus (Honjo, 1996), (2) six tandem ankyrin repeats that are necessary for transcriptional activity, and (3) a PEST sequence that regulates stability and protein turnover (Greenwald, 1994; Bray, 2006). The receptors are activated via interactions with Notch ligands, which are also type-I transmembrane proteins with multiple EGF-like repeats in their extracellular domain (D'Souza et al, 2008). The five mammalian Notch ligands are separated into two subgroups: Delta-like (Dll1, Dll3, and Dll4) or Serrate-like (Jagged1 and Jagged2), based on the structural similarity with their Drosophila homologues (Bray, 2006). Ultimately, the diverse

\footnotetext{
*Correspondence: Dr Y Kang; E-mail: ykang@princeton.edu
}

Received 6 July 2011; revised 3 October 2011; accepted 19 October 201 I; published online 10 November 2011 functions affected by the Notch pathway are dependent on the signalling interaction between neighbouring cells (Sprinzak et al, 2010).

The Notch pathway is activated when a signal-sending cell expressing a membrane-bound ligand physically interacts with a signal-receiving cell expressing a Notch receptor (Gray et al, 1999). Upon ligand binding, the Notch receptor is cleaved twice, first by an extracellular matrix metalloprotease (Brou et al, 2000) and then by the transmembrane protease complex $\gamma$-secretase, releasing the Notch intracellular domain (Schroeter et al, 1998; Mumm et al, 2000; Six et al, 2003) (Figure 1A). After dissociating from the cell membrane, the Notch intracellular domain translocates to the nucleus where it interacts with the DNA-binding protein CSL (Rbp-Jא in mice; CBF1 in humans) to affect transcriptional responses (Jarriault et al, 1995; Wu et al, 2000). In a recent example, genomic analysis using Chip-chip arrays demonstrated that the promoter region of Notch1-regulated genes were bound by CSL, which helped reveal several new CSL-dependent targets of Notch signalling (Hamidi et al, 2011). The most prominent targets of the Notch pathway include a set of basic helix-loop-helix factors of the hairy and enhancer of split (Hes) and Hes-related repressor protein (Hey) families (Iso et al, 2003; Kopan and Ilagan, 2009). These transcription factors execute Notch signalling functions, including maintenance of stem cells, specification of cell fate, differentiation, proliferation, and apoptosis (Radtke and Raj, 2003). Although many of the essential pathway components have been identified, we are still uncovering new regulators of Notch signalling using fundamental developmental and molecular biology (Wang et al, 2008; Karaczyn et al, 2010; Sethi et al, 2010; Dalton et al, 2011).

\section{NOTCH SIGNALLING AND CANCER}

An oncogenic role for Notch was first demonstrated in T-cell acute lymphoblastic leukaemia (T-ALL) with the identification of a chromosomal translocation that resulted in the expression 

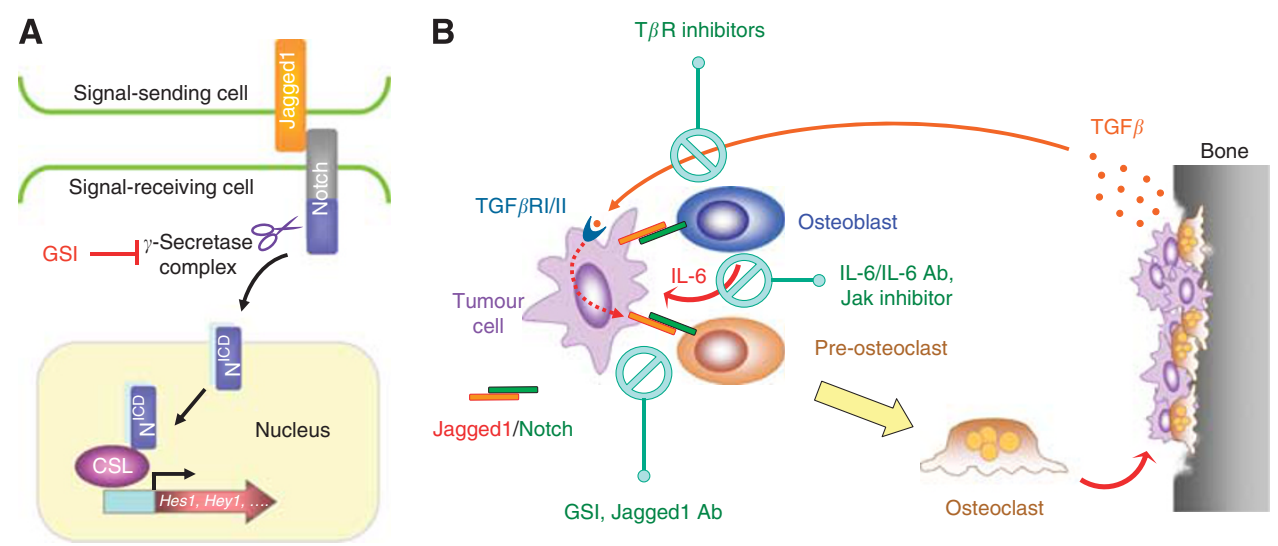

Figure I JaggedI/Notch signalling in bone metastasis. (A) Schematic representation of JaggedI/Notch mediated juxtacrine signalling between neighbouring cells. The Jagged I ligand expressed by the signal-sending cell is recognised by the Notch family receptors expressed by the signal-receiving cells and initiates a series of proteolytic cleavage events that liberates the intracellular domain of the Notch receptor ( $N^{\prime C D}$ ). $N^{1 C D}$ interacts with the DNA-binding protein CSL to turn it from a transcriptional repressor to an activator. $\gamma$-secretase inhibitor (GSI) blocks intracellular cleavage of Notch and inhibits Notch signalling. (B) Tumour-derived Jagged I promotes osteolytic bone metastasis of breast cancer. Jagged I is overexpressed in breast tumour cells that are highly metastatic to bone and engages bone stromal cells by activating Notch signalling in these cells. Notch signalling promotes the expression and secretion of IL-6, which feeds back to tumour cells to stimulate growth and resistance to chemotherapy. Meanwhile, Notch signalling directly activates osteoclast maturation, thereby exacerbating osteolytic bone metastasis. The destruction of bone matrix releases abundant amount of TGF- $\beta$, which further activates the expression of Jagged I in tumour cells through a Smad-dependent fashion. The findings indicate the therapeutic potential of reducing osteolytic bone metastasis by targeting Notch, TGF- $\beta$ and IL-6 through different classes of inhibitors. Figure adopted from Sethi et al (201 I).

of a truncated, constitutively active form of the Notch1 protein in T-cells (Ellisen et al, 1991). Experimental work using transgenic mouse models revealed that constitutive activity of the Notch pathway in hematopoietic progenitors drives the specification of an immature $\mathrm{T}$-cell lineage, which then evolves into a highly aggressive monoclonal T-cell leukaemia with the cooperation of additional mutations (Pear et al, 1996; Radtke et al, 1999). Further clinical evaluation revealed activating mutations of Notch1 in more than $50 \%$ of patient cases (Weng et al, 2004). The characterisation of aberrant Notch signalling in T-cell leukaemia provided a foundation for researchers to explore the pathway's importance in other cancers (Table 1).

The Notch pathway has been implicated in the tumourigenesis of several solid tumour malignancies including, but not limited to, non-small cell lung adenocarcinoma (Dang et al, 2000), melanoma (Bedogni et al, 2008), ovarian carcinoma (Park et al, 2006), medulloblastoma (Hallahan et al, 2004), and Kaposi's sarcoma (Curry et al, 2005). The pathway has also been shown to contribute to the pathogenesis of breast cancer. Constitutive activation of the Notch pathway in mammary tissue leads to the development of breast cancer in distinct mouse models. These studies employed the mouse mammary tumour virus (MMTV) system, which led to the identification of the Notch1 and Notch4 gene loci as frequent viral insertion sites that consequently resulted in the development of breast adenocarcinoma (Gallahan and Callahan, 1987). Similar to the mechanism in T-ALL, the MMTV insertion resulted in the constitutive expression of an active truncated form of the Notch receptor, revealing an oncogenic role for Notch signalling in mammary tissue (Jhappan et al, 1992; Dievart et al, 1999). Several studies have since shown that constitutive activation of the pathway confers tumourigenic properties to mammary epithelial cells (Raafat et al, 2004; Zang et al, 2007). However, unlike T-ALL, it is ambiguous as to how the pathway is aberrantly activated in human solid tumour malignancy, as underlying genomic mutations are rarely found in patient samples. Considering the lack of evidence showing genetic mutations in Notch, there should be greater emphasis on uncovering the source of Notch signalling activation in solid tumours. One avenue of exploration is characterising the potential heterogeneity of ligand and receptor expression within the primary tumour. Along this line of reasoning, a possible mechanism would involve a subset of primary tumour cells expressing Notch ligands, which have been shown to be aberrantly induced by local microenvironment paracine signals (Zeng et al, 2005), may activate the Notch pathway in a different subset of primary tumour, or signal-receiving, cells. Such a scenario would parallel Notch signalling events that take place during development when executing cell fate decisions (e.g. lateral specification) (Heitzler and Simpson, 1991; Greenwald, 1998; Sassoli et al, 2011).

Beyond its role in tumourigenesis, Notch signalling has also been associated with cancer progression, particularly through its regulation of the epithelial-to-mesenchymal transition (EMT). Epithelial-to-mesenchymal transition is a conserved cellular programme that confers mesenchymal features to epithelial cells during development and is postulated to provide epithelial tumour cells with migratory properties, facilitating early steps in metastasis such as invasion. The Notch pathway regulates EMT with the contribution of several players and processes, such as $\operatorname{TGF} \beta$ signalling (Timmerman et al, 2004; Zavadil et al, 2004), $\beta$-catenin activity (Balint et al, 2005), the transcription factor Slug (Leong et al, 2007), and most recently hypoxia (Bedogni et al, 2008; Sahlgren et al, 2008). Notch signalling has also shown to directly regulate mediators of invasion, such as matrix metalloproteinase- 9 and vascular endothelial growth factor (Wang et al, 2006). Interestingly, the Notch ligand Jagged1 is also associated with cancer progression; analysis of clinical samples revealed that it is highly expressed in metastatic prostate cancer compared with localised disease (Santagata et al, 2004) and overexpressed in breast cancer patients with poor prognosis (Reedijk et al, 2005). Despite these associations, until recently, the functional mechanism of Notch signalling in breast cancer metastasis was poorly defined.

\section{NOTCH SIGNALLING AND BONE METASTASIS}

Corroborating previously published data, we found that elevated expression of Jagged 1 was associated with an increased incidence of breast cancer relapse. These findings were extended by interrogating a separate clinical data set with more diverse outcome measures such as organ-specific metastasis, which showed that elevated Jagged1-expression levels was associated 
Table I Examples of tumour-intrinsic and extrinsic Notch signalling in cancer progression

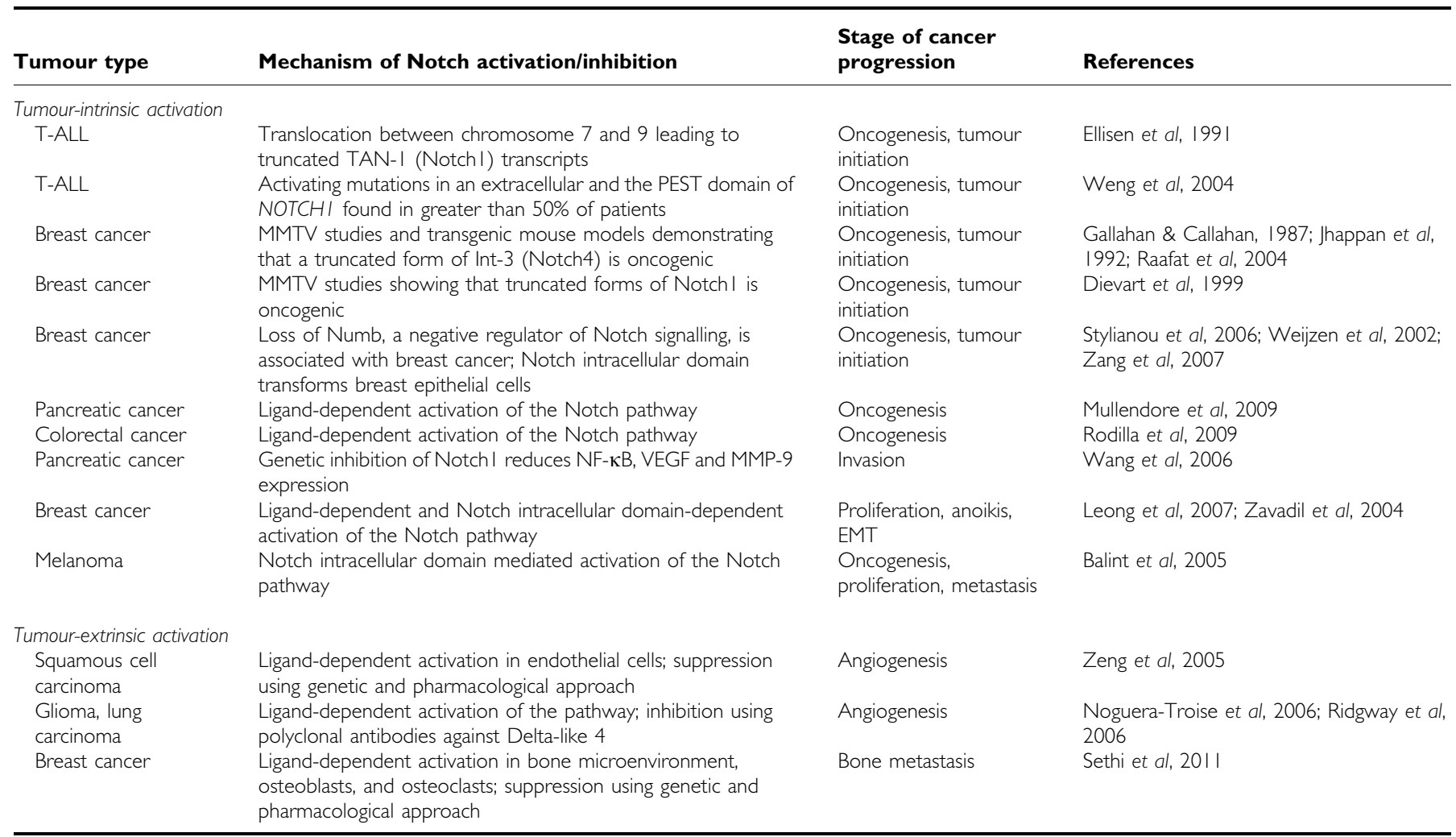

Abbreviations: EMT = epithelial-to-mesenchymal transition; MMP-9 = matrix metalloproteinase-9; MMTV = mouse mammary tumour virus; T-ALL = T-cell acute lymphoblastic leukaemia; VEGF = vascular endothelial growth factor.

with bone metastasis. Functional studies in mice demonstrated that Jagged1-expressing breast cancer cells promote bone metastasis by activating the Notch signalling pathway in the bone microenvironment (Sethi et al, 2011) (Figure 1B). These findings suggest a new paradigm for Notch signalling in breast cancer progression, defining a requirement for the pathway in the bone stroma as opposed to tumour cells during the formation of bone metastasis. Interestingly, a role for the Notch pathway in the tumour-associated stroma has been shown to facilitate other cancer-promoting functions, such as angiogenesis. In head and neck squamous cell carcinoma, cancer-mediated activation of the pathway in endothelial cells supported tumour neovascularisation and angiogenesis (Zeng et al, 2005). Similarly, Delta-mediated Notch signalling was shown to facilitate tumour angiogenesis by maintaining the sprouting integrity of the developing tumour vasculature (Noguera-Troise et al, 2006).

In the bone microenvironment, tumour-derived Jagged1 engaged the Notch pathway in two distinct cell types: osteoblasts and osteoclasts. Jaggedl-mediated activation of the pathway in osteoblasts conferred a growth advantage to bone metastatic tumour cells. Mechanistic studies revealed that the proliferative gain was dependent on osteoblast-secreted IL-6, which was transcriptionally regulated by the Notch pathway and its downstream target Heyl (Sethi et al, 2011). Independent studies have shown that IL- 6 is associated with a poor prognosis in breast cancer (Zhang and Adachi, 1999; Salgado et al, 2003) and is capable of supporting tumour growth in stromal-dependent mechanisms (Sasser et al, 2007; Studebaker et al, 2008; Ara et al, 2009). In neuroblastoma (Ara et al, 2009) and multiple myeloma (Mitsiades et al, 2006), IL-6 derived from stromal cells was shown to be an important mediator between cancer cells and the bone microenvironment by supporting tumour survival and affecting osteoclast differentiation, respectively. Of note, activation of other developmental pathways in osteoblasts has also been shown to promote bone metastasis (Sethi and Kang, 2011). Paracrine Sonic Hedgehog signalling by prostate cancer cells was shown to promote bone metastasis by inducing osteoblast differentiation through a Gli1-dependent mechanism (Zunich et al, 2009).

Jagged1-expressing tumour cells demonstrated a severe osteolytic phenotype in mice, suggesting a potential effect of tumourderived Jagged1 on osteoclastogenesis (Sethi et al, 2011). Coculture experiments between Jagged1-expressing tumour cells and primary bone marrow cells demonstrated a strong induction of osteoclastogenesis. Often, tumour cells affect osteoclast maturation indirectly through osteoblast-dependent regulation of RANKL and OPG signalling (Lu et al, 2009); however, our results supported a distinct mechanism as Jagged1-expressing tumour cells directly associated with pre-osteoclasts to promote their maturation. These findings were supported by the direct application of recombinant Jagged1 protein to pre-osteoclasts, which demonstrated a strong upregulation of osteoclast maturation (Sethi et al, 2011). Transcriptional profiling of osteoclast-differentiation markers more definitively confirmed these results. Integrating these findings, it appears that tumour-derived Jagged1 directly engages Notch pathway in pre-osteoclasts, promoting their differentiation into mature, multinucleated osteoclasts, a mechanism that can help explain the severe osteolytic phenotype observed in Jagged1-mediated bone metastasis.

\section{TARGETING MOLECULAR MEDIATORS OF NOTCH-DEPENDENT BONE METASTASIS}

When metastatic cancer cells spread to the bone, the influence of the microenvironment and resultant adaptations undertaken by tumour cells alter them in ways that render them resistant to 
cell-autonomous therapies that would otherwise effectively treat their corresponding primary tumour (Emmenegger and Kerbel, 2010; Karlou et al, 2010). Experimental mouse models have also shown the therapeutic inadequacies of targeted agents in treating metastatic lesions (Man et al, 2002; Francia et al, 2009). These observations collectively support the rational for targeting the microenvironment of the metastatic lesion, in conjunction with the tumour cells directly, to better control disease that has spread to distant organs. The molecular mechanisms underlying Jagged1mediated bone metastasis suggested that targeting the Notch pathway in the bone microenvironment might prove as an effective strategy in the treatment of bone metastasis. Currently, $\gamma$-secretase inhibitors (GSI) are small molecules that can potently disrupt the Notch pathway; they are also gaining popularity as anticancer agents based on preclinical studies (Shih Ie and Wang, 2007). Combining these pieces of information, we decided to test whether administration of GSI could interrupt communication between Jagged1-expressing tumour cells and the bone microenvironment in an attempt to treat breast cancer bone metastasis. GSI therapy reversed the bone metastasis-promoting functions of Jagged 1 by disrupting the Notch pathway in bone stromal cells. Gene-expression analysis of bone metastases demonstrated that GSI-treated mice displayed a downregulation of Notch target genes in the tumour-associated stromal compartment, including a decrease in IL-6 levels. Overall, the results revealed a stromaldependent mechanism for Notch signalling in supporting tumour outgrowth in the bone and suggest that targeting the pathway in the tumour-associated stroma may improve treatment for breast cancer bone metastasis (Sethi et al, 2011).

Importantly, other mediators and regulators contributed to Notch signalling in bone metastasis and therefore represent potential targets for therapeutic intervention. Jagged1 was shown to be the prime mediator of Notch-dependent bone metastasis and would be an ideal target for monoclonal antibody therapy as it is a cell-surface protein. Monoclonal antibodies targeting other Notch pathway ligands, such as Delta-like 4, have been shown to disrupt angiogenesis and tumour growth, demonstrating the potential therapeutic advantage of targeting Notch ligands (Noguera-Troise et al, 2006; Ridgway et al, 2006). The cytokine IL-6 is released by osteoblasts in response to Jagged1-mediated bone metastasis and a potential therapeutic target. Tocilizumab is a humanised monoclonal antibody against the interleukin-6 receptor (IL-6R) that has been approved to be used as an immunosuppressive drug in the treatment of rheumatoid arthritis. Additional inhibitors of IL-6 and its downstream Jak-Stat pathways are also under active clinical development.

Of pathological significance, the TGF- $\beta$ pathway was shown to regulate Jagged 1 expression during breast cancer bone metastasis. TGF- $\beta$ is sequestered in the bone matrix and often times released in response to bone degradation, a process that is largely at play during osteolytic bone metastasis (Korpal et al, 2009). TGF- $\beta$ was established as a critical regulator of Jagged1-mediated bone metastasis. Enforced expression of Jagged1 in SMAD4-knockdown breast cancer cells, which are severely impaired in their ability to form productive osteolytic bone metastases due to the defective reception of microenvironment TGF- $\beta$ cues (Kang et al, 2003, $2005)$, restored the bone metastasis-promoting functions of these malignant cells. The TGF- $\beta$ pathway has also been targeted by therapeutic agents currently being tested in clinical trials (Korpal and Kang, 2010) and would be a candidate pathway to disrupt in combination with Notch signalling in the treatment of breast cancer bone metastasis.

As we appreciate the therapeutic potential of molecular mediators that support communication between tumour cells and the bone microenvironment in the generation of bone metastasis, it will be critical to test the efficacy of these agents in the appropriate patient population. With respect to Notch signalling in bone metastasis, there is preliminary data that link Jagged 1 and IL-6 expression to the basal-like subtype of breast cancer (Sansone et al, 2007; Sethi et al, 2011, unpublished observation). It is therefore imperative to design robust clinical trials, evaluating these agents in select patient groups that are most likely to benefit from the particular therapeutic intervention. These agents should be administered either alone or in combination with other inhibitors targeting the cross-talk between tumour and bone stromal cells in the treatment of bone metastasis.

\section{REFERENCES}

Ara T, Song L, Shimada H, Keshelava N, Russell HV, Metelitsa LS, Groshen SG, Seeger RC, DeClerck YA (2009) Interleukin-6 in the bone marrow microenvironment promotes the growth and survival of neuroblastoma cells. Cancer Res 69: 329-337

Artavanis-Tsakonas S, Rand MD, Lake RJ (1999) Notch signaling: cell fate control and signal integration in development. Science 284: 770-776

Balint K, Xiao M, Pinnix CC, Soma A, Veres I, Juhasz I, Brown EJ, Capobianco AJ, Herlyn M, Liu ZJ (2005) Activation of Notch1 signaling is required for beta-catenin-mediated human primary melanoma progression. J Clin Invest 115: 3166-3176

Bedogni B, Warneke JA, Nickoloff BJ, Giaccia AJ, Powell MB (2008) Notch1 is an effector of Akt and hypoxia in melanoma development. J Clin Invest 118: $3660-3670$

Bray SJ (2006) Notch signalling: a simple pathway becomes complex. Nat Rev Mol Cell Biol 7: 678-689

Brou C, Logeat F, Gupta N, Bessia C, LeBail O, Doedens JR, Cumano A, Roux P, Black RA, Israel A (2000) A novel proteolytic cleavage involved in Notch signaling: the role of the disintegrin-metalloprotease TACE. Mol Cell 5: 207-216

Curry CL, Reed LL, Golde TE, Miele L, Nickoloff BJ, Foreman KE (2005) Gamma secretase inhibitor blocks Notch activation and induces apoptosis in Kaposi's sarcoma tumor cells. Oncogene 24: 6333-6344

D'Souza B, Miyamoto A, Weinmaster G (2008) The many facets of Notch ligands. Oncogene 27: 5148-5167

Dalton HE, Denton D, Foot NJ, Ho K, Mills K, Brou C, Kumar S (2011) Drosophila Ndfip is a novel regulator of Notch signaling. Cell Death Differ 18: $1150-1160$
Dang TP, Gazdar AF, Virmani AK, Sepetavec T, Hande KR, Minna JD, Roberts JR, Carbone DP (2000) Chromosome 19 translocation, overexpression of Notch3, and human lung cancer. J Natl Cancer Inst 92: $1355-1357$

Dievart A, Beaulieu N, Jolicoeur P (1999) Involvement of Notch1 in the development of mouse mammary tumors. Oncogene 18: $5973-5981$

Ellisen LW, Bird J, West DC, Soreng AL, Reynolds TC, Smith SD, Sklar J (1991) TAN-1, the human homolog of the Drosophila notch gene, is broken by chromosomal translocations in $\mathrm{T}$ lymphoblastic neoplasms. Cell 66: 649-661

Emmenegger U, Kerbel RS (2010) Cancer: Chemotherapy counteracted. Nature 468: $637-638$

Francia G, Man S, Lee CJ, Lee CR, Xu P, Mossoba ME, Emmenegger U, Medin JA, Kerbel RS (2009) Comparative impact of trastuzumab and cyclophosphamide on HER-2-positive human breast cancer xenografts. Clin Cancer Res 15: 6358-6366

Gallahan D, Callahan R (1987) Mammary tumorigenesis in feral mice: identification of a new int locus in mouse mammary tumor virus (Czech II)-induced mammary tumors. J Virol 61: 66-74

Gray GE, Mann RS, Mitsiadis E, Henrique D, Carcangiu ML, Banks A, Leiman J, Ward D, Ish-Horowitz D, Artavanis-Tsakonas S (1999) Human ligands of the Notch receptor. Am J Pathol 154: 785-794

Greenwald I (1994) Structure/function studies of lin-12/Notch proteins. Curr Opin Genet Dev 4: 556-562

Greenwald I (1998) LIN-12/Notch signaling: lessons from worms and flies Gene Dev 12: $1751-1762$ 
Hallahan AR, Pritchard JI, Hansen S, Benson M, Stoeck J, Hatton BA, Russell TL, Ellenbogen RG, Bernstein ID, Beachy PA, Olson JM (2004) The SmoA1 mouse model reveals that notch signaling is critical for the growth and survival of sonic hedgehog-induced medulloblastomas. Cancer Res 64: 7794-7800

Hamidi H, Gustafason D, Pellegrini M, Gasson J (2011) Identification of novel targets of CSL-dependent Notch signaling in hematopoiesis. PLoS One 6: e20022

Heitzler P, Simpson P (1991) The choice of cell fate in the epidermis of Drosophila. Cell 64: 1083-1092

Honjo T (1996) The shortest path from the surface to the nucleus: RBP-J kappa/Su(H) transcription factor. Genes Cells 1: 1-9

Iso T, Kedes L, Hamamori Y (2003) HES and HERP families: multiple effectors of the Notch signaling pathway. J Cell Physiol 194: 237-255

Jarriault S, Brou C, Logeat F, Schroeter EH, Kopan R, Israel A (1995) Signalling downstream of activated mammalian Notch. Nature 377: $355-358$

Jhappan C, Gallahan D, Stahle C, Chu E, Smith GH, Merlino G, Callahan R (1992) Expression of an activated Notch-related int-3 transgene interferes with cell differentiation and induces neoplastic transformation in mammary and salivary glands. Genes Dev 6: 345-355

Kang Y, He W, Tulley S, Gupta GP, Serganova I, Chen CR, Manova-Todorova K, Blasberg R, Gerald WL, Massague J (2005) Breast cancer bone metastasis mediated by the Smad tumor suppressor pathway. Proc Natl Acad Sci USA 102: 13909-13914

Kang Y, Siegel PM, Shu W, Drobnjak M, Kakonen SM, Cordon-Cardo C, Guise TA, Massague J (2003) A multigenic program mediating breast cancer metastasis to bone. Cancer Cell 3: 537-549

Karaczyn A, Bani-Yaghoub M, Tremblay R, Kubu C, Cowling R, Adams TL, Prudovsky I, Spicer D, Friesel R, Vary C, Verdi JM (2010) Two novel human NUMB isoforms provide a potential link between development and cancer. Neural Development 5: 31

Karlou M, Tzelepi V, Efstathiou E (2010) Therapeutic targeting of the prostate cancer microenvironment. Nat Rev Urol 7: 494-509

Kopan R, Ilagan MX (2009) The canonical Notch signaling pathway: unfolding the activation mechanism. Cell 137: 216-233

Korpal M, Kang Y (2010) Targeting the transforming growth factor-beta signalling pathway in metastatic cancer. Eur J Cancer 46: 1232-1240

Korpal M, Yan J, Lu X, Xu S, Lerit DA, Kang Y (2009) Imaging transforming growth factor-beta signaling dynamics and therapeutic response in breast cancer bone metastasis. Nat Med 15: 960-966

Leong KG, Niessen K, Kulic I, Raouf A, Eaves C, Pollet I, Karsan A (2007) Jagged1-mediated Notch activation induces epithelial-to-mesenchymal transition through Slug-induced repression of E-cadherin. J Exp Med 204: $2935-2948$

Logeat F, Bessia C, Brou C, LeBail O, Jarriault S, Seidah NG, Israel A (1998) The Notch1 receptor is cleaved constitutively by a furin-like convertase. Proc Natl Acad Sci USA 95: 8108-8112

Lu X, Wang Q, Hu G, Van Poznak C, Fleisher M, Reiss M, Massague J, Kang Y (2009) ADAMTS1 and MMP1 proteolytically engage EGF-like ligands in an osteolytic signaling cascade for bone metastasis. Gene Dev 23: $1882-1894$

Man S, Bocci G, Francia G, Green SK, Jothy S, Hanahan D, Bohlen P, Hicklin DJ, Bergers G, Kerbel RS (2002) Antitumor effects in mice of lowdose (metronomic) cyclophosphamide administered continuously through the drinking water. Cancer Res 62: 2731-2735

Mitsiades CS, Mitsiades NS, Munshi NC, Richardson PG, Anderson KC (2006) The role of the bone microenvironment in the pathophysiology and therapeutic management of multiple myeloma: interplay of growth factors, their receptors and stromal interactions. Eur J Cancer 42: $1564-1573$

Mullendore ME, Koorstra JB, Li YM, Offerhaus GJ, Fan X, Henderson CM, Matsui W, Eberhart CG, Maitra A, Feldmann G (2009) Ligand-dependent Notch signaling is involved in tumor initiation and tumor maintenance in pancreatic cancer. Clin Cancer Res 15: 2291-2301

Mumm JS, Schroeter EH, Saxena MT, Griesemer A, Tian X, Pan DJ, Ray WJ, Kopan R (2000) A ligand-induced extracellular cleavage regulates gammasecretase-like proteolytic activation of Notch1. Mol Cell 5: 197-206

Noguera-Troise I, Daly C, Papadopoulos NJ, Coetzee S, Boland P, Gale NW, Lin HC, Yancopoulos GD, Thurston G (2006) Blockade of Dll4 inhibits tumour growth by promoting non-productive angiogenesis. Nature 444: $1032-1037$

Park JT, Li M, Nakayama K, Mao TL, Davidson B, Zhang Z, Kurman RJ, Eberhart CG, Shih Ie M, Wang TL (2006) Notch3 gene amplification in ovarian cancer. Cancer Res 66: 6312-6318
Pear WS, Aster JC, Scott ML, Hasserjian RP, Soffer B, Sklar J, Baltimore D (1996) Exclusive development of T cell neoplasms in mice transplanted with bone marrow expressing activated Notch alleles. J Exp Med 183: $2283-2291$

Raafat A, Bargo S, Anver MR, Callahan R (2004) Mammary development and tumorigenesis in mice expressing a truncated human Notch4/Int3 intracellular domain (h-Int3sh). Oncogene 23: $9401-9407$

Radtke F, Raj K (2003) The role of Notch in tumorigenesis: oncogene or tumour suppressor? Nat Rev Cancer 3: 756-767

Radtke F, Wilson A, Stark G, Bauer M, van Meerwijk J, MacDonald HR, Aguet M (1999) Deficient T cell fate specification in mice with an induced inactivation of Notch1. Immunity 10: $547-558$

Reedijk M, Odorcic S, Chang L, Zhang H, Miller N, McCready DR, Lockwood G, Egan SE (2005) High-level coexpression of JAG1 and NOTCH1 is observed in human breast cancer and is associated with poor overall survival. Cancer Res 65: 8530-8537

Ridgway J, Zhang G, Wu Y, Stawicki S, Liang WC, Chanthery Y, Kowalski J, Watts RJ, Callahan C, Kasman I, Singh M, Chien M, Tan C, Hongo JA, de Sauvage F, Plowman G, Yan M (2006) Inhibition of Dll4 signalling inhibits tumour growth by deregulating angiogenesis. Nature 444: $1083-1087$

Rodilla V, Villanueva A, Obrador-Hevia A, Robert-Moreno A, FernandezMajada V, Grilli A, Lopez-Bigas N, Bellora N, Alba MM, Torres F, Dunach M, Sanjuan X, Gonzalez S, Gridley T, Capella G, Bigas A, Espinosa L (2009) Jagged1 is the pathological link between Wnt and Notch pathways in colorectal cancer. Proc Natl Acad Sci USA 106: $6315-6320$

Sahlgren C, Gustafsson MV, Jin S, Poellinger L, Lendahl U (2008) Notch signaling mediates hypoxia-induced tumor cell migration and invasion. Proc Natl Acad Sci USA 105: 6392-6397

Salgado R, Junius S, Benoy I, Van Dam P, Vermeulen P, Van Marck E, Huget P, Dirix LY (2003) Circulating interleukin-6 predicts survival in patients with metastatic breast cancer. Int J Cancer 103: 642-646

Sansone P, Storci G, Tavolari S, Guarnieri T, Giovannini C, Taffurelli M, Ceccarelli C, Santini D, Paterini P, Marcu KB, Chieco P, Bonafe M (2007) IL-6 triggers malignant features in mammospheres from human ductal breast carcinoma and normal mammary gland. J Clin Invest 117: $3988-4002$

Santagata S, Demichelis F, Riva A, Varambally S, Hofer MD, Kutok JL, Kim R, Tang J, Montie JE, Chinnaiyan AM, Rubin MA, Aster JC (2004) JAGGED1 expression is associated with prostate cancer metastasis and recurrence. Cancer Res 64: 6854-6857

Sasser AK, Sullivan NJ, Studebaker AW, Hendey LF, Axel AE, Hall BM (2007) Interleukin-6 is a potent growth factor for ER-alpha-positive human breast cancer. FASEB J 21: 3763-3770

Sassoli C, Pini A, Mazzanti B, Quercioli F, Nistri S, Saccardi R, Zecchi-Orlandini S, Bani D, Formigli L (2011) Mesenchymal stromal cells affect cardiomyocyte growth through juxtacrine Notch-1/Jagged-1 signaling and paracrine mechanisms: clues for cardiac regeneration. J Mol Cell Cardiol 51: 399-408

Schroeter EH, Kisslinger JA, Kopan R (1998) Notch-1 signalling requires ligand-induced proteolytic release of intracellular domain. Nature 393: $382-386$

Sethi N, Kang Y (2011) Dysregulation of developmental pathways in bone metastasis. Bone 48: 16-22

Sethi N, Dai X, Winter CG, Kang Y (2011) Tumor-derived JAGGED1 promotes osteolytic bone metastasis of breast cancer by engaging notch signaling in bone cells. Cancer Cell 19: 192-205

Sethi N, Yan Y, Quek D, Schupbach T, Kang Y (2010) Rabconnectin-3 is a functional regulator of mammalian Notch signaling. J Biol Chem 285: $34757-34764$

Shih Ie M, Wang TL (2007) Notch signaling, gamma-secretase inhibitors, and cancer therapy. Cancer Res 67: 1879-1882

Six E, Ndiaye D, Laabi Y, Brou C, Gupta-Rossi N, Israel A, Logeat F (2003) The Notch ligand Deltal is sequentially cleaved by an ADAM protease and gamma-secretase. Proc Natl Acad Sci USA 100: 7638-7643

Sprinzak D, Lakhanpal A, Lebon L, Santat LA, Fontes ME, Anderson GA, Garcia-Ojalvo J, Elowitz MB (2010) Cis-interactions between Notch and Delta generate mutually exclusive signalling states. Nature 465: $86-90$

Studebaker AW, Storci G, Werbeck JL, Sansone P, Sasser AK, Tavolari S, Huang T, Chan MW, Marini FC, Rosol TJ, Bonafe M, Hall BM (2008) Fibroblasts isolated from common sites of breast cancer metastasis enhance cancer cell growth rates and invasiveness in an interleukin-6dependent manner. Cancer Res 68: 9087-9095 
Stylianou S, Clarke RB, Brennan K (2006) Aberrant activation of notch signaling in human breast cancer. Cancer Res 66: $1517-1525$

Timmerman LA, Grego-Bessa J, Raya A, Bertran E, Perez-Pomares JM, Diez J, Aranda S, Palomo S, McCormick F, Izpisua-Belmonte JC, de la Pompa JL (2004) Notch promotes epithelial-mesenchymal transition during cardiac development and oncogenic transformation. Gene dev 18: $99-115$

Wang XY, Yin Y, Yuan H, Sakamaki T, Okano H, Glazer RI (2008) Musashil modulates mammary progenitor cell expansion through proliferin-mediated activation of the Wnt and Notch pathways. Mol cell biol 28: $3589-3599$

Wang Z, Banerjee S, Li Y, Rahman KM, Zhang Y, Sarkar FH (2006) Down-regulation of notch-1 inhibits invasion by inactivation of nuclear factor-kappaB, vascular endothelial growth factor, and matrix metalloproteinase-9 in pancreatic cancer cells. Cancer Res 66: 2778 - 2784

Weijzen S, Rizzo P, Braid M, Vaishnav R, Jonkheer SM, Zlobin A, Osborne BA, Gottipati S, Aster JC, Hahn WC, Rudolf M, Siziopikou K, Kast WM, Miele L (2002) Activation of Notch-1 signaling maintains the neoplastic phenotype in human Ras-transformed cells. Nat Med 8: 979-986

Weng AP, Ferrando AA, Lee W, Morris JPt, Silverman LB, Sanchez-Irizarry C, Blacklow SC, Look AT, Aster JC (2004) Activating mutations of NOTCH1 in human $\mathrm{T}$ cell acute lymphoblastic leukemia. Science 306: $269-271$

Wu L, Aster JC, Blacklow SC, Lake R, Artavanis-Tsakonas S, Griffin JD (2000) MAML1, a human homologue of Drosophila mastermind, is a transcriptional co-activator for NOTCH receptors. Nat Genet 26: $484-489$

Zang S, Ji C, Qu X, Dong X, Ma D, Ye J, Ma R, Dai J, Guo D (2007) A study on Notch signaling in human breast cancer. Neoplasma 54: 304-310

Zavadil J, Cermak L, Soto-Nieves N, Bottinger EP (2004) Integration of TGF-beta/Smad and Jagged1/Notch signalling in epithelial-to-mesenchymal transition. Embo J 23: $1155-1165$

Zeng Q, Li S, Chepeha DB, Giordano TJ, Li J, Zhang H, Polverini PJ, Nor J, Kitajewski J, Wang CY (2005) Crosstalk between tumor and endothelial cells promotes tumor angiogenesis by MAPK activation of Notch signaling. Cancer Cell 8: 13-23

Zhang GJ, Adachi I (1999) Serum interleukin-6 levels correlate to tumor progression and prognosis in metastatic breast carcinoma. Anticancer Res 19: $1427-1432$

Zunich SM, Douglas T, Valdovinos M, Chang T, Bushman W, Walterhouse D, Iannaccone P, Lamm ML (2009) Paracrine sonic hedgehog signalling by prostate cancer cells induces osteoblast differentiation. Mol cancer 8: 12 